\title{
Positive responses of strawberry (Fragaria x ananassa Duch.) explants to salicylic and iron nanoparticle application under salinity conditions
}

\author{
Ali akbar Mozafari ${ }^{1,2} \cdot$ Sajede Dedejani ${ }^{1} \cdot$ Nasser Ghaderi ${ }^{1,2}$ \\ Received: 19 February 2018 / Accepted: 7 May 2018 / Published online: 21 May 2018 \\ (c) The Author(s) 2018
}

\begin{abstract}
Key message Salicylic acid and iron nanoparticles application improved morphological and growth-related characteristics of the strawberry plantlets' under in vitro culture and Positive responses to salinity stress.

Abstract Strawberry explants cv. Queen Elisa were cultured under in vitro conditions to monitor the application of salicylic acid (SA) and iron nanoparticles (INs) in response to salinity. Three levels of salinity (0,50, and $100 \mathrm{mM} \mathrm{NaCl})$, three levels of iron nanoparticles $(0.0,0.08$, and $0.8 \mathrm{ppm})$, and three SA concentrations $(0.0,0.01,0.05 \mathrm{mM})$ were applied. Salinity showed negative effects on growth parameters, pigment content, relative water content (RWC) and membrane stability index (MSI), and disturbed the ionic exchange in mature plants. The application of SA showed a positive and compensating effect that somewhat reversed the effects of salinity. INs, as a readily available alternative to iron sulphate, have also shown positive impacts on strawberry plants under salinity conditions. The application of both SA and INs improved all growthrelated parameters and increased the pigment content, RWC, MSI, and iron and potassium contents of the mature plants, and decreased the content of sodium under salinity conditions. The highest concentration of INs $(0.8 \mathrm{ppm})$ showed the highest positive effect for almost all measured parameters. While no statistical difference was detectable between high $(0.05 \mathrm{mM})$ and medium $(0.01 \mathrm{mM})$ levels of SA under salinity conditions, under non-stress conditions the difference was significant for growth-related parameters. Hence, if the aim is to produce strawberry explants or transplants using tissue culture, the application of higher SA levels is appropriate; but for decreasing the negative effects of salinity, medium levels of SA seem to be effective.
\end{abstract}

Keywords Tissue culture $\cdot$ Sodium $\cdot$ Potassium $\cdot$ Relative water content $\cdot$ Pigment

\section{Introduction}

Salinity, or salt stress, is one of the most detrimental abiotic stresses, disturbing the absorption of nutritional elements, and causing decreased water uptake and indirect drought stress (Bashir et al. 2016). It has been accepted that saline conditions normally increase the uptake of sodium $\left(\mathrm{Na}^{+}\right)$

Communicated by Sergio J. Ochatt.

Ali akbar Mozafari

a.mozafari@uok.ac.ir

1 Department of Horticultural Sciences, Faculty of Agriculture, University of Kurdistan, P. O. Box 416, Sanandaj 66177-15175, Iran

2 Research Center of Strawberry Breeding and Improvement, University of Kurdistan, P. O. Box 416, Sanandaj 66177-15175, Iran while decreasing the uptake of potassium $\left(\mathrm{K}^{+}\right)$and calcium $\left(\mathrm{Ca}^{2+}\right)$. High-saline conditions, depending on the severity of the stress, lead to significant declines in growth- and yield-related parameters (Mickelbart et al. 2015). Decrease in leaf area and photosynthesis under salinity stress, resulting in reductions in the shoot and root weight and final yield of various plants such as strawberry (Yaghubi et al. 2016), raspberry (Neocleous and Vasilakakis 2007), gooseberry (Miranda et al. 2014), turfgrasses (Sekar 2016), and tomato (Rivero et al. 2014), have been well documented. Additionally, salt stress disturbs numerous vital physiological processes such as enzyme activity and photosynthesis rate. Also, due to stomata malfunction under salinity, altered gas exchange, and damage to pigments, salinity conditions usually trigger higher production of reactive oxygen species (Saed-Moucheshi et al. 2014), leading to decreased photosynthesis efficiency (Cardeñosa et al. 2015). Reduction in chlorophyll and/or carotenoid content under salinity stress 
in a wide range of plant species, including wheat (Sapre and Verma 2014), barley (Zahedi et al. 2016), strawberry (Yaghubi et al. 2016), beans (Taïbi et al. 2016), and corn (Saed-Moocheshi et al. 2014), has also been reported. In recent years, due to the its ability to provide quick feedback, its virus-free and controlled environment, in vitro culture has become widely used in some research areas related to plant science. Consequently, a number of studies have considered the effects of salinity on nutritional elements such as $\mathrm{NaCl}$ in in vitro conditions; these studies have highlighted the negative influence of salinity on phyisological and growth-related traits in strawberry (Quiroz et al. 2017).

Strawberry (Fragaria $\times$ ananassa Duch.), a fruit plant with acceptable taste and flavor, high levels of fiber, ascorbic acid, and potassium, and anti-carcinogenic properties, is a significant plant in human nutrition. It is normally classified as susceptible to salinity (Bryla and Scagel 2014). Large amounts of saline cultivation areas in Iran and the demonstrated negative impacts of salinity on both the quantity and quality of strawberry plants and fruit have led researchers to monitor different methods and techniques to improve the tolerance of strawberry to salinity conditions. Subsequently, some reports related to the effectiveness of phytohormones in this regard have been published (Ferchichi et al. 2016). Salicylic acid (SA) has been recognized as an important phytohormone that plays a significant role in signaling pathways under environmental stresses, triggering quick responses to stressful conditions (Jamali and Eshghi 2015). Idrees et al. (2011) reported that the adverse impacts of salinity on plants can be improved by application of appropriate concentrations of SA, which can protect photosynthetic pigments and enhance the activities of antioxidative compounds and enzymes (Idrees et al. 2013). However, the proper content and concentration of this phytohormone to achieve the best response in strawberry and how to manage the improvement of tolerance to salinity stress have remained unexplored.

The interaction between salinity stress and both macroand micronutrient composition in plants has not yet been fully understood; however, micronutrients are acknowledged to be more affected by salinity stress (Fathi et al. 2016). Iron is a micronutrient vital for chlorophyll formation and photosynthesis rate in plants, and has a crucial role in plants' enzymatic and biochemical pathways. Moreover, strawberry fruit quality could be directly altered by iron availability (Valentinuzzi et al. 2015). In line with research related to the effects of iron as a micronutrient, the application of nanomaterials due to their unique magnetic, electrical, mechanical, optical, and chemical properties, has recently increased in agriculture and plant-tissue culture (Sabaghnia and Janmohammadi 2015). Nano-compounds, such as those made with iron nanoparticles, can be rapidly and completely absorbed by plants and available in the tissues for use (Askary et al. 2016).
Because of the documented negative impact of salinity stress, along with the relative lack of studies of SA and iron in the form of nanoparticles and, more importantly, their interaction in tissue culture of strawberry, the current study aims to determine the best combination of these compounds for producing high-quality plants in the presence of salinity stress. Also, the study aims to explore the logical relationships between different physiological and growth-related traits under salinity conditions.

\section{Materials and methods}

\section{Plant materials and growth conditions}

A three-factor factorial experiment based on completely random design in 2015 under in vitro conditions was carried out on strawberry (Fragaria $\times$ ananassa Duch.) cv. Queen Elisa to test the effect of $\mathrm{NaCl}$, as a salinity-inducing compound, and the plants' responses to the combined application of salicylic acid (SA) and iron nanoparticles (INs) under in vitro culture. Therefore, in the current study, strawberry cuttings were prepared from previous in vitro cultured plants in the horticultural lab of the University of Kurdistan, in Sanandaj, Kurdistan, Iran. Murashige and Skoog (1962) used as a medium culture for emergence of roots and shoots from the cuttings ( $2.5 \mathrm{~cm}$ in length). Three levels of sodium chloride $(\mathrm{NaCl})$ (Merck KGaA company) at 0,50 , and $100 \mathrm{mM} \mathrm{NaCl}$; three levels of SA (Merck KGaA company) at $0.0,0.08$, and $0.8 \mathrm{ppm}$; and three levels of iron nanoparticles at $0.0,0.01$, and $0.05 \mathrm{mM}$ nano-iron were applied. FeEDTA $\left(\mathrm{Na}_{2} \mathrm{EDTA}=37.3 \mathrm{ppm}+\mathrm{FeSO}_{4} \cdot 7 \mathrm{H}_{2} \mathrm{O}=27.8 \mathrm{ppm}\right)$ in $27 \mathrm{ppm}$ concentration was considered as $0.0 \mathrm{ppm}$ iron nanoparticles, and defined as the control. All cuttings cultured in the jars containing nano-iron particle that coated with L-Sistein (Sigma Aldridge company Ltd.). The growth medium contained 3\% sucrose (Merck KGaA company), $0.8 \%$ agarose (Merck KGaA company), $2 \mathrm{mg} \mathrm{L}^{-1}$ benzyl adenine (BA) (Sigma Aldridge company Ltd.), and $0.01 \mathrm{mg}$ $\mathrm{L}^{-1}$ indole acetic acid (IAA) (Sigma Aldridge company Ltd.). The $\mathrm{pH}$ of the medium was adjusted to 5.8 using $\mathrm{NaOH}$ or $\mathrm{HCl}$. Then $40 \mathrm{~mL}$ of each prepared medium mixture was placed in $250 \mathrm{~mL}$ glass jars. After each jar was autoclaved for $15 \mathrm{~min}$ at $121{ }^{\circ} \mathrm{C}$ and 1.2 bar, different concentrations of salicylic acid were added to the jars by filtering. The explanted tissues were then kept in a growth chamber at $16 / 8 \mathrm{light} /$ dark photoperiod conditions (38 $\mu \mathrm{E}$ $\mathrm{m}^{-2} \mathrm{~s}^{-1}$ ) at $21 \pm 2{ }^{\circ} \mathrm{C}$ temperature and $50-60 \%$ humidity. The experiment was continued for 60 days to measure the final total weight of the plants. 


\section{Measurement of traits}

After the cuttings were regenerated, the number of branches per regenerated plant was counted in each jar. The effect of $\mathrm{NaCl}$ treatments on the number branches for the cultured cuttings was analyzed using one-way ANOVA in a completely randomized design and mean comparison according to least significant difference. No significant difference was observed between means across the application of $50 \mathrm{mM} \mathrm{NaCl}$ and $100 \mathrm{mM} \mathrm{NaCl}$ compared to control; therefore, data for the application of $100 \mathrm{mM} \mathrm{NaCl}$ were set aside and the experiment was continued with the application of $50 \mathrm{mM} \mathrm{NaCl}$ and the control $(0 \mathrm{mM} \mathrm{NaCl})$. Afterward, mean comparison of the effect of INs following two-factor factorial ANOVA for $\mathrm{NaCl}$ and IN application as two factors was carried out on the number of branches per plant. The results indicated no significant difference between the control $(0.0 \mathrm{ppm})$ and $0.08 \mathrm{ppm}$ IN application sliced across $0 \mathrm{mM} \mathrm{NaCl}$ and $50 \mathrm{~mm} \mathrm{NaCl}$. Accordingly, data related to jars with $0.08 \mathrm{ppm}$ IN application were removed, and the experiment was continued with 0.0 and $0.8 \mathrm{ppm}$ IN application. Finally, all parameters were measured on two levels of $\mathrm{NaCl}$ application $(0$ and $50 \mathrm{mM}$ ), two levels of IN application ( 0.0 and $0.8 \mathrm{ppm})$, and three levels of SA (0.0, 0.01 , and $0.05 \mathrm{mM})$.

\section{Growth-related traits}

Shoot fresh and dry weight, root dry weight, total dry weight of the plants, number of branches, and shoot length were measured as growth-related traits using a precise ruler and scale.

\section{Pigment content}

Sub-plant sample tissue $(0.1 \mathrm{~g})$ was homogenized and powdered in liquid nitrogen, then $10 \mathrm{~mL}$ acetone (80\%) was added to extract the pigments. After centrifugation at $5000 \mathrm{rpm}$ for $5 \mathrm{~min}$, the supernatant was separated for light and photometry readings. The contents of total chlorophyll, chlorophyll a, chlorophyll $b$, and carotenoid as pigments were measured based on the method of Lichtenthaler and Buschmann (2001) using a spectrophotometer (UV-2100 model suv NEW JERSEY).

For total carbohydrate content, $0.1 \mathrm{~g}$ of fresh tissue was ground finely in liquid nitrogen, then mixed with $5 \mathrm{~mL}$ ethanol 95\%; next, the supernatant was transferred to a falcon tube and centrifuged (HETTCH model MICRO Germany) for $10 \mathrm{~min}$ at $3500 \mathrm{rpm}$. The final supernatants were transferred to other falcon tubes in a bain marie at $100{ }^{\circ} \mathrm{C}$ for $20 \mathrm{~min}$. The final solutions were cooled to room temperature and the absorption was measured at $625 \mathrm{~nm}$ wavelength.

\section{Physiological traits}

Fresh tissues from the plantlet samples were cut and weighed as fresh weight, saturated weight, and dry weight. Relative water content (RWC) as a physiological trait was then measured based on these weights using the following formula (Karimi et al. 2012):

RWC $(\%)=\frac{(\text { Fresh weight }- \text { Dry weight })}{(\text { Saturated weight }- \text { Dry weight })} \times 100$

The samples' membrane stability index was measured based on the method of Sairam (1994).

\section{Nutritional elements}

The plantlets' iron, sodium, and potassium contents were measured using the method of Gupta et al. (2007), in which the samples are mixed with HCI and flame atomic absorption (Perkin Elmer company, model 200) is applied.

\section{Statistical analysis}

This study was carried out based on a three-way ANOVA (three-factor full factorial) experiment arranged in a completely randomized design with three replications. Each replication consisted of four sub-samples for each in vitro unit (thus for each treatment combination, a total of $3 \times 4$ (e.g. 12) explants were analyzed); in other words, each of the three replications consisted of four sub-replications. The mean of the four sub-samples in each plot was used as the trait's value for each replication. The test of normality was implemented to test the distribution of the ANOVA's model residuals. Mean comparison for the treatments was carried out based on the least significant difference method. SAS statistical software v. 9.4 was used for data analysis and Excel 2016 for drawing charts.

\section{Results}

\section{Growth-related traits}

The highest mean values for shoot fresh and dry weight, and number of branches were obtained with the application of INs and SA under no salinity stress (Table 1). The lowest mean values for these traits were obtained with the highest salinity stress conditions and no use of either SA or INs. The application of SA or iron nanoparticles increased fresh, dry weight and length of shoot at all salinity levels. Root dry weight decreased under salinity conditions. In contrast, the application of INs and SA at higher concentrations led to higher root dry weight. The application of both SA and IN 
Table 1 Three-way interaction mean comparison for salinity, salicylic acid, and iron nanoparticles related to growth parameters

\begin{tabular}{|c|c|c|c|c|c|c|c|c|}
\hline $\mathrm{NaCl}(\mathrm{mM})$ & IN (ppm) & $\mathrm{SA}(\mathrm{mM})$ & Number of branches & Shoot length $(\mathrm{cm})$ & $\begin{array}{l}\text { Shoot fresh } \\
\text { weight }(\mathrm{g})\end{array}$ & $\begin{array}{l}\text { Shoot dry } \\
\text { weight }(\mathrm{g})\end{array}$ & Root dry weight (g) & $\begin{array}{l}\text { Total dry } \\
\text { weight }(\mathrm{g})\end{array}$ \\
\hline \multirow{5}{*}{$\mathbf{0}$} & \multirow{3}{*}{0} & 0 & 4.1ef & $3.66 b$ & $1.04 \mathrm{e}$ & $0.15 \mathrm{e}$ & $0.021 b$ & $0.17 \mathrm{ef}$ \\
\hline & & 0.01 & $6.76 \mathrm{~d}$ & $2.59 \mathrm{efg}$ & $1.23 \mathrm{~d}$ & $0.25 \mathrm{~d}$ & $0.007 \mathrm{gh}$ & $0.21 \mathrm{de}$ \\
\hline & & 0.05 & $11.44 \mathrm{~b}$ & $1.16 \mathrm{~h}$ & $2.95 b$ & $0.41 \mathrm{~b}$ & $0.003 \mathrm{i}$ & $0.41 \mathrm{~b}$ \\
\hline & \multirow{3}{*}{0.8} & $\mathbf{0}$ & $4.33 \mathrm{e}$ & $4.38 \mathrm{a}$ & $1.24 \mathrm{~d}$ & $0.19 \mathrm{~d}$ & $0.027 a$ & $0.22 \mathrm{~d}$ \\
\hline & & 0.01 & $9.33 \mathrm{c}$ & $3.5 \mathrm{bc}$ & $1.58 \mathrm{c}$ & $0.25 \mathrm{c}$ & $0.015 \mathrm{c}$ & $0.26 \mathrm{c}$ \\
\hline \multirow{7}{*}{100} & & 0.05 & 16.11a & $2.13 \mathrm{~g}$ & $3.16 a$ & $0.44 a$ & $0.005 \mathrm{hi}$ & $0.45 a$ \\
\hline & \multirow{3}{*}{0} & 0 & $2.44 \mathrm{~h}$ & $2.46 f g$ & $0.63 \mathrm{~g}$ & $0.06 \mathrm{~h}$ & $0.01 \mathrm{ef}$ & $0.07 \mathrm{i}$ \\
\hline & & 0.01 & $2.96 \mathrm{gh}$ & $2.39 \mathrm{~g}$ & $0.87 f$ & $0.11 \mathrm{fg}$ & $0.008 \mathrm{fg}$ & $0.12 \mathrm{~h}$ \\
\hline & & 0.05 & $3.55 \mathrm{efg}$ & $2.22 \mathrm{~g}$ & $0.97 \mathrm{ef}$ & $0.14 \mathrm{efg}$ & 0.008 fgh & 0.15 fgh \\
\hline & \multirow{3}{*}{0.8} & 0 & $3.2 \mathrm{fgh}$ & $3.26 \mathrm{bcd}$ & $0.86 \mathrm{f}$ & $0.11 \mathrm{~g}$ & $0.012 \mathrm{~d}$ & $0.12 \mathrm{gh}$ \\
\hline & & 0.01 & $3.36 \mathrm{efgh}$ & $3.03 \mathrm{cde}$ & $0.97 \mathrm{ef}$ & $0.15 \mathrm{ef}$ & $0.012 \mathrm{de}$ & $0.16 f g$ \\
\hline & & 0.05 & $4.33 \mathrm{e}$ & 2.93def & $1.06 \mathrm{e}$ & $0.17 \mathrm{de}$ & $0.009 f g$ & $0.18 \mathrm{ef}$ \\
\hline
\end{tabular}

In each column the means with the same letter(s) are not significantly different (LSD $<5 \%)$

The bolded data show maximum difference in each column

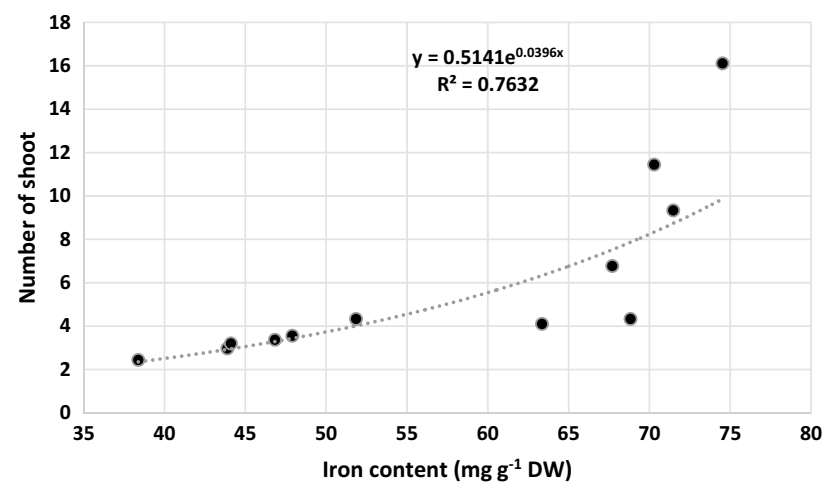

Fig. 1 Relationship between plants' iron content and number of shoot

led to increases in the total dry weight of the explants, but this was greater under no-stress conditions. The number of shoots showed a positive exponential relationship with the plants' iron content (Fig. 1).

\section{Pigment contents}

The lowest content of total chlorophyll was obtained with no application of either INs or SA under salinity conditions, while the highest content was found for both the application of Ins with $0.05 \mathrm{mM} \mathrm{SA}$ and for no $\mathrm{NaCl}$ application (Table 2). Relatively similar results were obtained for chlorophyll a, chlorophyll b, and carotenoid contents (Table 2). Pigment content negatively responded to higher levels of salinity. Application of SA positively compensated for the negative effects of salinity: higher levels of SA resulted in higher contents of all four measured pigments. A positive impact of SA on pigments was also observed under the no-stress condition. The response of pigment content to the application of INs was positive. Both chlorophyll a and total chlorophyll showed a rapid and significant response to an increase in IN application, although the response of chlorophyll $\mathrm{b}$ was lower than that of the other pigments.

\section{Physiological traits}

Salinity increased the content of total soluble carbohydrate (TSC); higher concentrations of SA also resulted in higher TSC content (Table 2). The highest content of carbohydrate was observed for the highest concentration of SA $(0.05 \mathrm{mM})$. Under both salinity levels and all SA concentrations, the application of INs increased the carbohydrate content. In contrast to the results for TSC, the membrane stability index and relative water content decreased in response to high salinity levels (Table 2). The application of higher concentrations of SA and INs led to increases in both RWC and MSI. The highest values for RWC and MSI resulted from the application of both INs and SA at the highest level $(0.05 \mathrm{mM})$ under conditions of no salinity; the lowest values were obtained for no application of either SA or IN under salinity condition. An examination of the relationship between the strawberry plants' iron content and MSI (Fig. 2) showed a highly linear relationship $\left(\mathrm{R}^{2}=0.99\right)$.

\section{Nutritional elements}

The reaction of sodium to higher levels of both SA and INs was negative. The higher the concentration of both SA and INs, the lower the content of sodium in the explants (Table 3). However, the levels of potassium and iron in explants in response to SA and INs were similar and their 
Table 2 Three-way interaction mean comparison for salinity, salicylic acid, and iron nanoparticles related to pigment content and physiological parameters

\begin{tabular}{|c|c|c|c|c|c|c|c|c|c|}
\hline $\mathrm{NaCl}(\mathrm{mM})$ & IN (ppm) & $\mathrm{SA}(\mathrm{mM})$ & $\begin{array}{l}\text { Chl a }\left(\mathrm{mg} \mathrm{g}^{-1}\right. \\
\text { FW) }\end{array}$ & $\begin{array}{l}\mathrm{Chl} \mathrm{b}\left(\mathrm{mg} \mathrm{g}^{-1}\right. \\
\text { FW) }\end{array}$ & $\begin{array}{l}\text { Car }\left(\mathrm{mg} \mathrm{g}^{-1}\right. \\
\mathrm{FW})\end{array}$ & $\begin{array}{l}\text { ChlT }\left(\mathrm{mg} \mathrm{g}^{-1}\right. \\
\text { FW) }\end{array}$ & $\begin{array}{l}\text { TSC }\left(\mathrm{mg} \mathrm{g}^{-1}\right. \\
\text { FW) }\end{array}$ & MSI (\%) & RWC (\%) \\
\hline & & 0 & $1.11 \mathrm{~d}$ & $0.203 b-e$ & $0.514 \mathrm{e}$ & $1.31 \mathrm{~d}$ & $26.34 \mathrm{~g}$ & $77.39 \mathrm{e}$ & $81.94 b$ \\
\hline & $\mathbf{0}$ & 0.01 & $1.33 \mathrm{bc}$ & $0.218 \mathrm{a}-\mathrm{e}$ & $0.614 \mathrm{c}$ & $1.55 \mathrm{c}$ & $28.69 \mathrm{fg}$ & $86.39 \mathrm{c}$ & 84.17ab \\
\hline \multirow[t]{6}{*}{ 0 } & & 0.05 & 1.38ab & 0.245ab & $0.654 a b$ & $1.63 b$ & $29.85 \mathrm{fg}$ & $88.51 \mathrm{bc}$ & $86.42 \mathrm{a}$ \\
\hline & & 0 & $1.29 \mathrm{c}$ & $0.228 \mathrm{a}-\mathrm{d}$ & $0.58 \mathrm{~d}$ & $1.52 \mathrm{c}$ & $32.8 \mathrm{ef}$ & $83.27 \mathrm{~d}$ & 85.45ab \\
\hline & 0.8 & 0.01 & $1.44 a b$ & $0.24 a b c$ & $0.64 b c$ & $1.64 \mathrm{ab}$ & $35.38 \mathrm{de}$ & 90.01ab & 86.08ab \\
\hline & & 0.05 & $1.44 a$ & $0.258 \mathrm{a}$ & $0.677 a$ & $1.75 a$ & $38.69 \mathrm{~cd}$ & 91.15a & 87.95a \\
\hline & & 0 & $0.73 \mathrm{~h}$ & $0.14 \mathrm{f}$ & $0.371 \mathrm{~g}$ & $0.87 \mathrm{~h}$ & 35.58de & $47.75 \mathrm{i}$ & $57.02 \mathrm{f}$ \\
\hline & $\mathbf{0}$ & 0.01 & $0.84 \mathrm{~g}$ & $0.168 \mathrm{ef}$ & $0.446 \mathrm{f}$ & $1.01 \mathrm{~g}$ & $58.77 \mathrm{~b}$ & $53.47 \mathrm{~h}$ & $67.96 \mathrm{e}$ \\
\hline \multirow[t]{4}{*}{100} & & 0.05 & $0.97 \mathrm{e}$ & $0.183 \mathrm{def}$ & $0.491 \mathrm{e}$ & $1.15 \mathrm{e}$ & 62.56ab & $59.32 \mathrm{~g}$ & $71.12 \mathrm{c}-\mathrm{e}$ \\
\hline & & 0 & $0.88 f g$ & $0.166 \mathrm{ef}$ & $0.442 \mathrm{f}$ & $1.05 \mathrm{fg}$ & $40.7 \mathrm{c}$ & $55.18 \mathrm{~h}$ & $69.31 \mathrm{de}$ \\
\hline & 0.8 & 0.01 & $0.93 \mathrm{ef}$ & $0.19 \mathrm{c}-\mathrm{f}$ & $0.487 \mathrm{e}$ & $1.12 \mathrm{ef}$ & $63.44 a b$ & $58.19 \mathrm{~g}$ & $73.32 \mathrm{~cd}$ \\
\hline & & 0.05 & $1.06 \mathrm{~d}$ & $0.201 \mathrm{~b}-\mathrm{e}$ & $0.513 \mathrm{e}$ & $1.26 \mathrm{~d}$ & $65.45 \mathrm{a}$ & $63.75 f$ & $74.11 \mathrm{c}$ \\
\hline
\end{tabular}

In each column the means with the same letter(s) are not significantly different $(\mathrm{LSD}<5 \%)$

The bolded data show maximum difference in each column

IN iron nanoparticle, SA salicylic acid, Chl chlorophyll, ChlT total chlorophyll, Car carotenoid, TSC soluble carbohydrate, MSI membrane stability index, $R W C$ relative water content

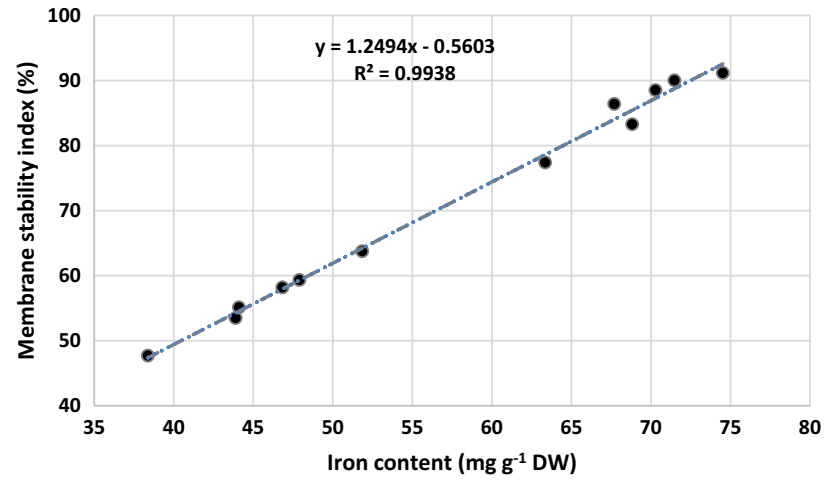

Fig. 2 Relationship between plants' iron content and membrane stability index

contents increased as the concentrations of both SA and IN rose. Sodium content under all levels of SA and INs increased as the salinity rose. The application of SA and INs under salinity conditions compensated somewhat for the negative effect of salinity and decreased the content of sodium in plants. Unlike the reaction of sodium content to salinity, the contents of potassium and iron under all levels of SA and INs declined with increases in salinity. The ratio of sodium per potassium $(\mathrm{Na} / \mathrm{K})$ to salinity was positive. This ratio negatively responded to the application of SA and INs. Under all salinity levels, application of higher concentrations of SA and INs resulted in a decrease in the ratio of $\mathrm{Na} / \mathrm{K}$. It is worth mentioning that that a linear relationship between iron content and $\mathrm{Na} / \mathrm{K}$ ratio in strawberry plants was detectable, and showed a negative trend (Fig. 3).

\section{Discussion}

Plants' tolerance to environmental stresses such as salinity can be determined using different parameters. These parameters can be classified as physiological and/or photosynthetic traits, biochemical traits, nutritional-content traits, and growth-related parameters. In this study different parameters were measured to cover types of these indices. Salinity negatively affected the shoot dry and fresh weight along with the number of shoots and the plants' total dry weight. In contrast, SA and IN application compensated for the negative effect of salinity on these traits and led to higher growth parameters. Root dry weight decreased in response to salinity, while SA and IN application led increased root dry weight. Furthermore, the application of both SA and INs under conditions of no salinity also resulted in improvements in all growth parameters compared to the control plants. This positive effect of SA may be due to enhanced chlorophyll concentration and photosynthesis rate, along with the increased critical uptake of minerals such as iron by stressed plants treated with SA. Also, improvements in growth parameters with the application of INs is directly related to the characteristics of the nanoparticles. Toljamo et al. (2016) stated that exogenous application of SA stimulated the formation of roots and increased mineral uptake. Mozafari et al. (2017) showed that under in vitro conditions, the application of INs can effectively mitigate the negative effects of drought stress on strawberry plants; they also verified that the concentration of INs could be an important issue to be considered on adjusting the micronutrient 
Table 3 Three-way interaction mean comparison for salinity, salicylic acid, and iron nanoparticles related to measured elements

\begin{tabular}{lllllll}
\hline $\mathrm{NaCl}(\mathrm{mM})$ & $\mathrm{IN}(\mathrm{ppm})$ & $\mathrm{SA}(\mathrm{mM})$ & $\begin{array}{l}\text { Potassium } \\
\left(\mathrm{mg} \mathrm{g}^{-1} \mathrm{DW}\right)\end{array}$ & $\begin{array}{l}\text { Sodium }(\mathrm{mg} \\
\left.\mathrm{g}^{-1} \mathrm{DW}\right)\end{array}$ & $\mathrm{Na} / \mathrm{K}$ ratio & Iron $\left(\mathrm{mg} \mathrm{g}^{-1} \mathrm{DW}\right)$ \\
\hline \multirow{3}{*}{$\mathbf{0}$} & 0 & $24.97 \mathrm{~d}$ & $2.56 \mathrm{e}$ & $0.10 \mathrm{e}$ & $63.36 \mathrm{~d}$ \\
& 0 & 0.01 & $31.93 \mathrm{c}$ & $2.35 \mathrm{e}$ & $0.07 \mathrm{e}$ & $67.69 \mathrm{c}$ \\
& & 0.05 & $33.64 \mathrm{~b}$ & $1.99 \mathrm{e}$ & $0.06 \mathrm{e}$ & $70.29 \mathrm{bc}$ \\
& \multirow{2}{*}{$\mathbf{0 . 8}$} & $\mathbf{0 . 0 1}$ & $30.71 \mathrm{c}$ & $2.16 \mathrm{e}$ & $0.07 \mathrm{e}$ & $68.83 \mathrm{bc}$ \\
& & $\mathbf{3 5 . 1 5 7 a}$ & $1.93 \mathrm{e}$ & $0.06 \mathrm{e}$ & $71.48 \mathrm{~b}$ \\
& & $\mathbf{0 . 0 5}$ & $\mathbf{3 5 . 6 9 a}$ & $2.49 \mathrm{e}$ & $0.07 \mathrm{e}$ & $\mathbf{7 4 . 5 2 a}$ \\
$\mathbf{1 0 0}$ & $\mathbf{0}$ & 0.01 & $15.77 \mathrm{~h}$ & $\mathbf{3 9 . 3 6 a}$ & $\mathbf{2 . 5 0 a}$ & $38.38 \mathrm{~h}$ \\
& & 0.05 & $20.52 \mathrm{f}$ & $24.97 \mathrm{~cd}$ & $1.22 \mathrm{c}$ & $47.91 \mathrm{f}$ \\
& & 0 & $18.11 \mathrm{~g}$ & $30.04 \mathrm{~b}$ & $1.66 \mathrm{~b}$ & $44.11 \mathrm{~g}$ \\
& \multirow{2}{*}{0.8} & 0.01 & $20.73 \mathrm{f}$ & $23.26 \mathrm{~cd}$ & $1.12 \mathrm{~cd}$ & $46.84 \mathrm{fg}$ \\
& & 0.05 & $22.75 \mathrm{e}$ & $22.48 \mathrm{~d}$ & $0.99 \mathrm{~d}$ & $51.85 \mathrm{e}$ \\
\hline
\end{tabular}

In each column the means with the same letter(s) are not significantly different (LSD $<5 \%)$

The bolded data show maximum difference in each column

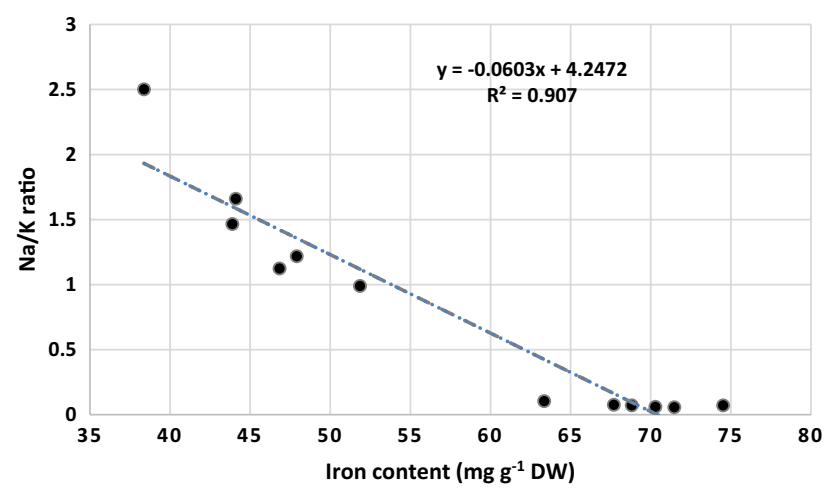

Fig. 3 Relationship between plants' iron content and $\mathrm{Na} / \mathrm{K}$ ratio

content of media for this plant. Waheed and Madi's (2016) results indicated maximum growth and chlorophyll content for palm-plant shoots observed after 75 days of culturing in a medium supplemented with $50 \mathrm{mg} \mathrm{L}^{-1} \mathrm{SA}$ in both stress and non-stress conditions. Also, in the this study, no statistical difference was detectable under salinity between high $(0.05 \mathrm{mM})$ and medium $(0.01 \mathrm{mM})$ levels of SA, while under control conditions the difference was significant for the growth parameters. Hence, if the aim is to produce strawberry explants or transplants using tissue-culture methods, application of higher SA levels is appropriate; however, to decrease the negative effects of salinity, also medium levels of INs seem to be effective.

Biochemical indices comprising chlorophyll a, chlorophyll b, total chlorophyll, and carotenoid contents decreased under salinity stress; in contrast, the application of SA and INs could compensate in part for the negative effects of salinity on these pigments. As claimed in studies such as Saied et al. (2005), strawberry is considered a saline-sensitive plant, and salinity stress has been proven to negatively affect its levels of chlorophylls and carotenoids; this both directly and indirectly leads to diminished productivity (Joseph et al. 2010). One of the negative effects of salinity is disturbance in the ionic exchange inside the plants. $\mathrm{NaCl}$ as a salinity-inducing compound usually results in lower or higher absorption of other anions or cations. This process can disturb the paths that contribute to the formation of pigments (Ashoori et al. 2015). Moreover, the final result of salinity conditions is usually the triggering of oxidative stress, bringing about damage to a variety of molecules inside the plants; these could include pigments (Omolade et al. 2016). On the other hand, the results of this study suggest that the application of compounds such as SA or nutritional elements such as iron in different forms might compensate for the negative effect of salinity on pigment content and photosynthesis rate in strawberry plants. Other authors, such as Karlidag et al. (2009) and Joseph et al. (2010), have achieved similar results related to the application of SA in strawberry plants. SA as a plant-growth regulator or phytohormone has been proven to trigger numerous physiological and metabolic reactions inside plant cells and organs, from emergence and development to response to stresses (Hayat et al. 2010). The positive impact of SA on salinity and drought stress has been well documented in different plant species; e.g. increases in the chlorophyll content of strawberry plants in response to salinity (Jamali et al. 2015) and drought stress (Ghaderi et al. 2015) with the application of SA have been reported. Along with this study, other studies (Osório et al. 2014; Torun et al. 2014) have also found a positive association between the chlorophyll content and iron content as micronutrients in the leaves. It has been reported that the synthesis of chlorophyll depends significantly on a sufficient content of micronutritional elements, especially iron, and that the shortage of 
these elements would result in leaf necrosis and decreased pigment content (Wu et al. 2013). It has been shown that iron compounds such as iron sulphate are relatively inactive in their movement through plant tissues (Jamali et al. 2015). Therefore, iron nanoparticles, which have electrical, optical, mechanical, magnetic, and unique chemical properties, can behave completely differently from their raw materials, and can be efficiently absorbed and carried inside the plant tissues (Moulson and Herbert 1990). In addition, higher applications of SA and INs under both stress and non-stress conditions resulted in higher pigment content in general.

As a physiological index, TSC increased in response to higher levels of salinity. Additionally, the application of both SA and INs resulted in an elevation in the carbohydrate content of strawberry explants. Geransayeh et al. (2015) reported that higher ascorbic acid and SA content in plants could result in induction of osmoregulator contents, such as some carbohydrates and amino acids, to manage the osmotic adjustment. In contrast, the levels of RWC and MSI were negatively affected by salinity, but the application of SA and IN compensated for these negative effects, resulting in higher RWC and lower MSI. Salinity usually lowers the osmotic potential inside the tissues, increasing the content of some carbohydrates that act as osmoregulation compounds. Additionally, owing to the lower potential of cells inside the plants during salinity stress, the root becomes more rigid, resulting in the suction of water from the soil requiring more energy than normal. RWC in this situation normally declines, as in the study of Nguyen et al. (2017), which reported severe reduction in the RWC of mangrove Avicennia marina under in vitro conditions. The application of SA and INs results in higher concentrations of osmoregulators in cells and tissues, causing higher osmotic adjustment inside the plant cells. The higher the osmotic adjustment, the higher the relative water content inside the cells; this results in a greater membrane stability index (Gulen et al. 2016). Similar results were found by Ghaderi et al. (2015) regarding the effect of SA, and by Mozafari et al. (2017) regarding the effects of SA and INs, on strawberry under drought stress.

Salinity increased the content of sodium $\left(\mathrm{Na}^{2+}\right)$, but decreased the content of potassium $\left(\mathrm{K}^{+}\right)$and iron $(\mathrm{Fe})$ in the strawberry explants. SA and IN application negatively affected the content of sodium in the stressed plants and increased the content of both potassium and iron. Thus, while salinity can directly and indirectly lead to iron deficiency in plants, the application of iron in this condition, particularly in absorbable form as nanoparticles, can counteract this effect. Earlier research has clearly shown that salinity affects plants' absorption of mineral elements. The most studied element in response to high $\mathrm{Na}$ content as a result of induced salinity is $\mathrm{K}$, and the ratio of $\mathrm{K}$ to $\mathrm{Na}$ is an vital issue for plants in determining how they face saline conditions. Under high levels of $\mathrm{Na}$, the absorption and exchange of $\mathrm{K}$ in cells is disrupted, leading to lower content of $\mathrm{K}$ in strawberry organs. Therefore, plants with higher K/Na ratios under salinity conditions can tolerate salinity stress more effectively than plants with lower ratios (Ghadakchiasl et al. 2017). In addition to K, the levels of other nutrients are reduced under salinity stress. Iron is a micronutrient that is normally reduced by salinity. Application of INs in the current study affected strawberry explants by adjusting the balance of nutrient exchange, particularly the content of potassium, in a positive manner. Meanwhile, some effective enzymes use $\mathrm{Fe}$ in a synergistic way to work properly in nutrient exchanges (Apse and Blumwald 2002). Moreover, SA can improve the K/Na ratio and increase the salinity tolerance of the treated plants. SA is an endogenous growth regulator participating in the regulation of the plant's physiological processes and controlling ion uptake by roots and stomatal conductivity (Hussein et al. 2007). Faghih et al. (2017) found that the treatment of strawberry plants with SA raised the content of potassium under saline conditions while decreasing the content of sodium.

\section{Conclusion}

In this study salinity negatively affected all measured traits, including such as pigment content, RWC, and MSI; disturbed the ion exchange in plants; and negatively affected growth parameters. The application of salicylic acid (SA) showed a positive and compensating effect to salinity stress. Iron nanoparticles (INs) as a readily available alternative particle to iron sulphate, have also shown positive impacts on strawberry tolerance to salinity under in vitro conditions. The application of both SA and INs improved all growth-related parameters and increased the pigemnt content, RWC, MSI, and iron and potassium contents of the matured plants; they also decreased the sodium content under salinity conditions. Under conditions of no salinity, the application of SA and INs in media effectively improved plants' growth, making them more likely to pass the vegetative stage than the control plants. Therefore, SA and INs are appropriate and effective compounds not only for producing strawberry transplants using tissue culture and micropropagation, but also for decreasing the negative influence of salinity on the whole plant. Furthermore, the highest concentration of INs $(0.8 \mathrm{ppm})$ showed the highest positive effect on almost all measured parameters. While no statistical difference was detectable between high $(0.05 \mathrm{mM})$ and medium $(0.01 \mathrm{mM})$ levels of SA under salinity condition, under non-stress conditions the difference was significant for growth-related parameters. Hence, if the aim is to produce strawberry explants or transplants using tissue-culture 
methods, application of higher SA levels is appropriate; but for decreasing the negative effects of salinity, medium levels of SA seem to be more effective.

Acknowledgements This work was supported by the University of Kurdistan under Grant [Number 4.14364].

Author contributions In this experiment AM designed experiment. SD performed experiment and assembled data under advice of AM and NG biochemical and physiological experiments and measurement supervised by NG. AM supervised morphological and in vitro culture physiological experiments and measurement. Data analysis has been performed by NG with the help of AM and SD results discuss and write of manuscript was performed by AM and NG.

Open Access This article is distributed under the terms of the Creative Commons Attribution 4.0 International License (http://creativeco mmons.org/licenses/by/4.0/), which permits unrestricted use, distribution, and reproduction in any medium, provided you give appropriate credit to the original author(s) and the source, provide a link to the Creative Commons license, and indicate if changes were made.

\section{References}

Apse MP, Blumwald E (2002) Engineering salt tolerance in plants. Curr Opin Biotechnol 13:146-150

Ashoori M, Ashraf S, Alipour ZT (2015) Investigating the effect of two species of mycorrhiza fungi and salinity on growth, function and chlorophyll content on Ocimum basilicum. Int J Agric Crop Sci 8:503

Askary M, Talebi SM, Amini F, Dousti Balout Bangan A (2016) Effect of $\mathrm{NaCl}$ and iron oxide nanoparticles on Mentha piperita essential oil composition. Environ Exp Biol 14:27-32

Bashir K, Kausar R, Shahzad SM, Ashraf M, Siddiqui AR, Ahmad A, Piracha MA (2016) Bio-associative effect of rhizobacteria on nodulation and yield of mungbean (Vigna radiata $\mathrm{L}$.) under saline conditions. J Appl Agric Biotechnol 2:23-37

Bryla D, Scagel C (2014) Limitations of $\mathrm{CaCl}_{2}$ salinity to shoot and root growth and nutrient uptake in 'Honeoye'strawberry (Fragaria $\times$ ananassa Duch.). J Hortic Sci Biotechnol 89:458-470

Cardeñosa V, Medrano E, Lorenzo P, Sánchez-Guerrero MC, Cuevas F, Pradas I, Moreno-Rojas JM (2015) Effects of salinity and nitrogen supply on the quality and health-related compounds of strawberry fruits (Fragaria $\times$ ananassa cv. Primoris). J Sci Food Agric 95:2924-2930

Faghih S, Ghobadi C, Zarei A (2017) Response of strawberry plant cv. 'Camarosa' to salicylic acid and methyl jasmonate application under salt stress condition. J Plant Growth Regul 12:1-9

Fathi A, Zahedi M, Torabian S, Khoshgoftar A (2016) Response of wheat genotypes to foliar spray of $\mathrm{ZnO}$ and $\mathrm{Fe}_{2} \mathrm{O}_{3}$ Nanoparticles under salt stress. J Plant Nutr 32:223-235

Ferchichi S, El Khouni A, Zorrig W, Atia A, Rabhi M, Gharsalli M, Abdelly C (2016) Nutrient uptake and use efficiencies in Medicago ciliaris under salinity. J Plant Nutr 39:932-941

Geransayeh M, Sepahvand S, Abdossi V (2015) Extending postharvest longevity and improving quality of strawberry (Fragaria Ananasa Duch. Cv. 'Gaviota') fruit by postharvest salicylic acid treatment. J Agric Study 3:17-36

Ghadakchiasl A, Mozafari A-a, Ghaderi N (2017) Mitigation by sodium nitroprusside of the effects of salinity on the morphophysiological and biochemical characteristics of Rubus idaeus under in vitro conditions. Physiol Mol Biol Plant 23:73-83
Ghaderi N, Normohammadi S, Javadi T (2015) Morpho-physiological responses of strawberry (Fragaria $\times$ ananassa) to exogenous salicylic acid application under drought stress. J Agric Sci Technol 17:167-178

Gulen H, Turhan E, Eris A (2016) Molecular and physiological responses of strawberry plants to abiotic stress strawberry: growth. Dev Dis 15:288

Gupta R, Wall T, Baxter L (2007) Impact of mineral impurities in solid fuel combustion. Springer, New York

Hayat Q, Hayat S, Irfan M, Ahmad A (2010) Effect of exogenous salicylic acid under changing environment: a review. Environ Exp Bot 68:14-25

Hussein M, Balbaa L, Gaballah M (2007) Salicylic acid and salinity effects on growth of maize plants. Res J Agric Biol Sci 3:321-328

Idrees M, Naeem M, Aftab T, Khan MMA (2011) Salicylic acid mitigates salinity stress by improving antioxidant defence system and enhances vincristine and vinblastine alkaloids production in periwinkle [Catharanthus roseus (L.) G. Don]. Acta Physiol Plant 33:987-999

Idrees M, Naeem M, Aftab T, Khan MA (2013) Salicylic acid restrains nickel toxicity, improves antioxidant defence system and enhances the production of anticancer alkaloids in Catharanthus roseus (L.). J Hazard Mater 252:367-374

Jamali B, Eshghi S (2015) Salicylic acid-induced salinity redressal in hydroponically grown strawberry. Commun Soil Sci Plant Anal 46:1482-1493

Jamali B, Eshghi S, Shahidi-Rad K (2015) Growth and fruit characteristics of strawberry cv. Selva as affected by different Application timing of salicylic acid under saline conditions. Inter $\mathbf{J}$ Fruit Sci 15:339-352

Joseph B, Jini D, Sujatha S (2010) Insight into the role of exogenous salicylic acid on plants grown under salt environment. Asian J Crop Sci 2:226-235

Karimi S, Yadollahi A, Nazari-Moghadam R, Imani A, Arzani K (2012) In vitro screening of almond (prunus dulcis (mill.)) genotypes for drought tolerance. J Biol Environ Sci 6:263-270

Karlidag H, Yildirim E, Turan M (2009) Exogenous applications of salicylic acid affect quality and yield of strawberry grown under antifrost heated greenhouse conditions. J Plant Nutr Soil Sci 172:270-276

Lichtenthaler HK, Buschmann C (2001) Chlorophylls and carotenoids: measurement and characterization by UV-VIS spectroscopy. Curr Protoc Food Anal Chem F4:3.1-3.8

Mickelbart MV, Hasegawa PM, Bailey-Serres J (2015) Genetic mechanisms of abiotic stress tolerance that translate to crop yield stability. Nat Rev Genet 16:237-251

Miranda D, Fischer G, Mewis I, Rohn S, Ulrichs C (2014) Salinity effects on proline accumulation and total antioxidant activity in leaves of the cape gooseberry (Physalis peruviana L.). J Appl Bot Food Qual 87:567-578

Moulson AJ, Herbert JM (1990) Electroceramics: materials, properties and applications. Chapman and Hall, London

Mozafari A, Havas F, Ghaderi N (2017) Application of iron nanoparticles and salicylic acid in in vitro culture of strawberries (Fragaria $\times$ ananassa Duch.) to cope with drought stress. Plant Cell Tissue Org Cult 33:1-13

Murashige TC, Skoog F (1962) A revised medium for rapid growth and bioassays with tobacco tissue cultures. Physiol Plant 15:473-497

Neocleous D, Vasilakakis M (2007) Effects of $\mathrm{NaCl}$ stress on red raspberry (Rubus idaeus L. 'Autumn Bliss'). Sci Hortic 112:282-289

Nguyen HT, Meir P, Sack L, Evans JR, Oliveira RS, Ball MC (2017) Leaf water storage increases with salinity and aridity in the mangrove Avicennia marina: integration of leaf structure, osmotic adjustment, and access to multiple water sources. Plant Cell Environ 13:433-450 
Omolade O, Müller A, Jung C, Melzer S (2016) In the present study, three Arabidopsis thaliana pop2 mutant lines with different T-DNA insertions in a gene coding $\gamma$-aminobutyric acid transaminase (GABA-TA) were screened for seed germination percentage, stress-induced oxidative damage, and GABA content and metabolism under various abiotic stresses including high temperature (42 C), low temperature (4 C), salinity $(\mathrm{NaCl})$, and osmotic stress (mannitol). Biol Plant 60:132-138

Osório J, Osório ML, Correia PJ, de Varennes A, Pestana M (2014) Chlorophyll fluorescence imaging as a tool to understand the impact of iron deficiency and resupply on photosynthetic performance of strawberry plants. Sci Hortic 165:148-155

Quiroz KA, Berríos M, Carrasco B, Retamales JB, Caligari PD, GarcíaGonzáles R (2017) Meristem culture and subsequent micropropagation of Chilean strawberry (Fragaria chiloensis (L.) Duch.). Biol Res 50:20-35

Rivero RM, Mestre TC, Mittler R, Rubio F, Garcia-sanchez F, Martinez V (2014) The combined effect of salinity and heat reveals a specific physiological, biochemical and molecular response in tomato plants. Plant Cell Environ 37:1059-1073

Sabaghnia N, Janmohammadi M (2015) Effect of nano-silicon particles application on salinity tolerance in early growth of some lentil genotypes. Anna UMCS Biol 69:39-55

Saed-Moocheshi A, Shekoofa A, Sadeghi H, Pessarakli M (2014) Drought and salt stress mitigation by seed priming with $\mathrm{KNO}_{3}$ and urea in various maize hybrids: an experimental approach based on enhancing antioxidant responses. J Plant Nutr 37:674-689

Saed-Moucheshi A, Pakniyat H, Pirasteh-Anosheh H, Azooz M (2014) Role of ROS as signaling molecules in plants. In: Ahmad P (ed) Reactive oxygen species, antioxidant network and signaling in plants. Springer, New York

Saied AS, Keutgen AJ, Noga G (2005) The influence of NaCl salinity on growth, yield and fruit quality of strawberry cvs. 'Elsanta' and 'Korona'. Sci Hortic 103:289-303

Sairam R (1994) Effects of homobrassinolide application on plant metabolism and grain yield under irrigated and moisture-stress conditions of two wheat varieties. Plant Growth Regul 14:173-181
Sapre S, Verma Y (2014) Biochemical responses of wheat (Triticum aestivum) varieties under salinity stress. Curr Adv Agric Sci 6:93-95

Sekar SK (2016) Efficacy of salinity mitigation on warm season turfgrasses. Cornell University, New York

Taïbi K, Taïbi F, Abderrahim LA, Ennajah A, Belkhodja M, Mulet JM (2016) Effect of salt stress on growth, chlorophyll content, lipid peroxidation and antioxidant defence systems in Phaseolus vulgaris L. S Afr J Bot 105:306-312

Toljamo A, Blande D, Kärenlampi S, Kokko H (2016) Reprogramming of strawberry (Fragaria vesca) root transcriptome in response to Phytophthora cactorum. PLoS ONE 11:e0161078

Torun AA, kaçar Y, Bicen B, Erdem N, Serce S (2014) In vitro screening of octoploid Fragaria chiloensis and Fragaria virginiana genotypes against iron deficiency. Turk J Agric For 38:169-179

Valentinuzzi F, Mason M, Scampicchio M, Andreotti C, Cesco S, Mimmo T (2015) Enhancement of the bioactive compound content in strawberry fruits grown under iron and phosphorus deficiency. J Sci Food Agric 95:2088-2094

Waheed A-M, Madi A (2016) Influence of salicylic acid (SA) and ascorbic acid (ASA) on in vitro propagation and salt tolerance of date palm ('Phoenix dactylifera' L.) cv. 'Nersy'. Aust J Crop Sci 10:969-988

Wu Y, Yu W, Li Y (2013) Effects of iron deficiency stress on photosynthetic characteristics and organelle iron content of strawberry seedlings. J Plant Nutr Fertil 4:12-27

Yaghubi K, Ghaderi N, Vafaee Y, Javadi T (2016) Potassium silicate alleviates deleterious effects of salinity on two strawberry cultivars grown under soilless pot culture. Sci Hortic 213:87-95

Zahedi MB, Razi H, Saed-Moucheshi A (2016) Evaluation of antioxidant enzymes, lipid peroxidation and proline content as selection criteria for grain yield under water deficit stress in barley. J Appl Biol Sci 10:34-51 